\title{
A QUESTÃO CLIMÁTICA DO NORDESTE BRASILEIRO E OS PROCESSOS DE DESERTIFICAÇÃO ${ }^{1}$
}

\author{
José Bueno Conti ${ }^{2}$
}

\begin{abstract}
RESUMO
O presente trabalho discute os processos de desertificação na região Nordeste do Brasil, nas áreas de clima Semi-árido, a partir da utilização do método das séries temporais. O quadro geral da análise indicou $49,7 \%$ das séries apresentando tendência crescente nas médias pluviométricas, configurando uma distribuição geográfica indiferenciada, apresentando, contudo, incidência maior no Rio Grande do Norte, Paraíba e Pernambuco, sobretudo no espaço compreendido entre o reverso continental da Borborema e chapada do Apodi e seus prolongamentos meridionais. Tal constatação indica que a precipitação em nível regional acompanha a tendência de elevação da média pluviométrica que vem sendo registrada nas últimas décadas, presumivelmente associada ao agravamento do efeito de estufa. Por outro lado, $50,3 \%$ revelaram tendência estável ou decrescente, as primeiras, com distribuição geográfica mal caracterizada, ao passo que as segundas agruparam-se em quatro manchas, sinalizadoras de indícios de desertificação localizada.
\end{abstract}

Palavras chave: clima, desertificação, semi-árido, nordeste.

\section{THE CLIMATIC ISSUE OF THE BRAZILIAN NORTHEAST AND THE DESERTIFICATION PROCESSES}

\begin{abstract}
This article discusses desertification processes in the semi arid climates at Northeast Brazilian Region, by use of temporal series method. The results indicates that $49,7 \%$ of the rainfall series data showed increase tendency configuring indistinct regional distribution presenting, however, more incidence at Rio Grande do Norte, Paraíba e Pernambuco states and, principally in the area well-known between Borborema plateau and Apodi meseta and its meridian prolonged. This fact indicates that regional mean rainfall follow the tendency of increase detected at the last decades, probably associated with greenhouse effect. By the other side, 50,3\% of the temporal series data showed stable or decrease tendency. The first one with uncharacterized geographical distribution and the second occurred in four small areas signalized as possible desertification areas.
\end{abstract}

Key words: climate, desertification process, semi arid, Northeast.

1 Palestra apresentada em mesa redonda do VI Simpósio Brasileiro de Climatologia, 13 a 16 de outubro de 2004, Aracaju, SE.

2 Professor Titular do Departamento de Geografia da Faculdade de Filosofia Letras e Ciências Humanas da USP. 


\section{A região semi-árida brasileira}

A região semi-árida do Nordeste brasileiro (o sertão) estende-se por cerca de 900 mil km² e caracteriza-se por médias pluviométricas anuais oscilando entre 300 e $800 \mathrm{~mm}$. Em sua porção nuclear (em torno de $500 \mathrm{mil}$ $\mathrm{km}^{2}$ ), a pluviometria anual é inferior a $600 \mathrm{~mm}$ (Ab'Saber, 1974,1977).

Manifesta-se de forma mais característica, numa área que se estende do litoral setentrional, da foz do rio Jaguaribe (latitude de $04^{\circ} 30^{\prime} \mathrm{S}$ ) à Ponta dos Três Irmãos (município de São Bento do Norte, RN, latitude de $05^{\circ}$ $\left.10^{\prime} \mathrm{S}\right)$, avançando pelo continente em direção ao vale do rio São Francisco até a latitude de $12^{\circ} \mathrm{S}$ ), apresentando-se de forma descontínua.

A região semi-árida é envolvida a Oeste, ao Sul e a Leste, por áreas mais úmidas, definindo uma faixa transicional muito variável. Em direção a Noroeste, vai se descaracterizando, a partir da Chapada do Ibiapaba, onde a estação seca se reduz a seis meses, passando para um quadro físico subúmido e cobertura vegetal de cerrado, embora ainda ocorram bolsões de vegetação xerofítica na bacia do rio Parnaíba, principalmente nos vales dos rios Piaúi e Gurguéia. A partir da depressão sanfranciscana, em direção a Oeste, o domínio semi-árido é limitado pelos chapadões cretácicos da Serra Geral, de clima subúmido e vegetação arbustiva, do tipo cerrado. Para Leste, no rumo do Atlântico, a transição é mais rápida, sendo constituída por uma faixa subúmida, de largura variando ente cinqüenta e cem quilômetros, correspondente à região colinosa conhecida como agreste, originalmente coberta por formações florestais caducifólias, hoje praticamente extintas.

O domínio semi-árido está longe de ser homogêneo, manifestando características distintas conforme os fatores geoecológicos locais. Constitui um mosaico variado de paisagens, já bem caracterizado por muitos estudiosos, desempenhando o relevo regional importante papel na determinação das diferenças (MELO, 1958; MONTEIRO, 1988).

Apesar de modesto, com altitudes máximas pouco superiores a 1000 $\mathrm{m}$, o relevo introduz modificações ambientais expressivas, decorrentes de situações de barlavento e sotavento. Em áreas mais elevadas, como a serra de Baturité e nos divisores entre a bacia do São Francisco e a dos rios que vertem para o Norte (chapada do Araripe, serra dos Cariris Velhos, da Boa Vista, Verde etc.), a semi-aridez é atenuada pelo efeito orográfico, ocorrendo enclaves úmidos ou "brejos": Juazeiro do Norte (precipitação média anual - pma 903,3 $\mathrm{mm}$ ), Barbalha (pma 1001,3 mm), Triunfo (pma $1141 \mathrm{~mm}$ ). Na periferia do domínio semi-árido, em pleno agreste, o relevo também é responsável pela ocorrência de uma "diagonal" úmida formada por planaltos de altitudes entre 800 e 1000 m, cujos valores de pma oscilam entre 750 e 1000 mm (ex. Garanhuns, 908,6 mm).

Por outro lado, a escassez de chuvas acentua-se nas depressões em geral, especialmente naquelas situadas em oposição de sotavento, como a vertente ocidental da serra dos Dois Irmãos, no Piauí, onde as localidades de Queimada Nova e Paulistana recebem, respectivamente, 398,0 mm e 560,9 $\mathrm{mm}$; e os vales do Pajeú e do Moxotó, em Pernambuco. Também há os exemplos de Inajá $(394,0 \mathrm{~mm})$, Moxotó $(429,9 \mathrm{~mm})$ e Floresta $(501,3 \mathrm{~mm})$. Poderíamos acrescentar, ainda, as depressões de Patos e Cabaceiras, na Paraíba, situando-se aí uma das localidades mais secas de todo o semi-árido: Cabaceiras, com 336,0 mm anuais. Destaca-se, ainda, a região entre Juazeiro e 
Paulo Afonso, onde, além da precipitação reduzida, a estiagem habitualmente estende-se por onze meses (NIMER, 1988).

Numa visão de conjunto, verifica-se que o core da mancha semiárida é definido por alinhamentos de relevo. As chapadas sedimentares cretácicas de Ibiapaba e seu prolongamento meridional, a serra dos Dois Irmãos, estabelecem os limites ocidentais, ao mesmo tempo em que o planalto da Borborema marca os limites orientais. Por outro lado, a chapada do Araripe, as serras da Baixa Verde e dos Cariris Velhos, alongadas no sentido leste-oeste, separam subdomínios no interior do semi-árido. Ao Norte, estende-se uma vasta área aplainada, esculpida em superfície de erosão e interrompida por manifestações de relevo residual (Baturité, serra dos Martins, serra da Pedra Branca) e por depressões ocupadas por bacias hidrográficas, onde correm rios intermitentes. Os melhores exemplos são as do Jaguaribe (artificialmente perenizado), do Acaraú, do Apodi-Mossoró e do Piranhas-Açu. Ocupam pediplanos coalescentes, formando grandes extensões horizontalizadas, com alguns campos de inselbergues, como o de Quixadá (bacia do Jaguaribe), constituído, dominantemente, por pegmatitos. A precipitação anual está em torno de $500 \mathrm{~mm}$ e a vegetação é de caatinga áspera.

Ao Sul das terras elevadas, representadas pelo eixo chapada do Araripe-serras dos Cariris Velhos-serra do Teixeira e seus prolongamentos, 0 quadro de semi-aridez não apresenta mudanças significativas, com grandes superfícies horizontalizadas, de solos rasos, drenagem intermitente, médias pluviométricas próximas de $500 \mathrm{~mm}$ e estiagens de nove a dez meses. As depressões locais são menos beneficiadas pela pluviosidade, acentuando pontualmente a aridez. Ao Sul do São Francisco, o trecho médio e superior do rio Vaza-Barris, conhecido como Raso da Catarina, constitui um dos mais secos do interior nordestino, como médias pluviométricas anuais entre 300 e 400 mm. Aí está a localidade de Quinjique que apresenta o "record" negativo de $311 \mathrm{~mm}$ anuais de precipitação.

Mais ao Sul a região de chuvas escassas se divide em dois segmentos separados pelas terras elevadas da chapada Diamantina, cuja altitude média é pouco superior a $1 \mathrm{mil} \mathrm{m}$. Na vertente interior, correspondente à depressão do São Francisco, a semi-aridez se manifesta de forma indiscutível (exemplos: Morpará, 760,0 mm; Barra, 759,8 e Xique-Xique, 815,3 mm), estendendo-se até o Norte de Minas Gerais, onde a localidade de Manga registra $892,6 \mathrm{~mm}$ anuais, ao passo que, na vertente atlântica, suas características são mais acentuadas na Bahia, nos trechos superior e médio do vale do rio de Contas (Jequié, 585,8 mm) e, em Minas, na bacia do Jequinhonha (Almenara, 908,3 mm).

No conjunto do quadro regional as médias térmicas são elevadas, acima de $26^{\circ} \mathrm{C}$ e a evaporação é intensa, produzindo acentuado deficit hídrico, expresso por uma drenagem intermitente, com características de torrencialidade.

O histórico da intervenção oficial nessa região remonta ao segundo Império. Pode-se lembrar apenas que, em 1936, foi criado por lei federal o Polígono das Secas, a fim de delimitar a área prioritária no recebimento de ajuda governamental no combate aos efeitos das estiagens. Seus limites foram várias vezes ampliados, ocupando, atualmente, $936993 \mathrm{~km} 2$.

Sobre esse quadro natural áspero, desenvolveu-se o longo processo de ocupação, que agora se aproxima dos quinhentos anos, durante os quais as 
práticas incorretas de exploração e uso deixaram conseqüências profundas e, em muitos casos, sem retorno, abrindo caminho para a degradação generalizada e a desertificação.

\section{A desertificação do nordeste brasileiro e a metodologia das séries temporais}

Estatisticamente, as séries temporais são indicadores quantitativos e sua análise tem por objetivo investigar o mecanismo gerador, descrever o comportamento e fazer prognósticos. Podem expressar tendências, ciclos e variabilidade relevantes ou se revelar aleatórias, derivando daí, seu interesse para a climatologia. Contudo, o perfil das séries, para ser confiável, exige grande quantidade de observações ao longo do tempo. A pesquisa que realizamos utilizou séries sempre superiores a sete décadas e nunca inferiores a cinco, não tendo sido estendidas além desses limites pela indisponibilidade de registros. A maioria dos estudos de séries temporais, mesmo em nível internacional, trabalha com poucas décadas e, mesmo em virtude da insuficiência de dados, os resultados têm sido considerados expressivos pela comunidade científica (GEIGER, 1974).

Adotamos a metodologia das séries temporais, considerando o fato de ter sido, até o presente, pouco praticada na região nordestina brasileira, sendo, portanto, uma oportunidade de testar sua eficácia. A tendência foi obtida trabalhando-se com os totais anuais, organizados em séries para cada localidade. Tais dados foram transformados em gráficos e ajustados das retas de tendências, expressos pela equação: $y=b \cdot x+a$, na qual "a" representa o coeficiente linear da reta ou intercepto e " $b$ " o coeficiente angular ou taxa de variação anual, pela técnica de regressão linear. Os gráficos foram traçados aplicando-se a técnica das médias móveis simples em escala de tempo anual, visando o "alisamento" das séries a fim de facilitar a análise. Para cada uma das séries foi calculado o nível descritivo do teste para detectar a tendência, ou seja, se a taxa de variação anual era nula, com significância expressa em milímetro/ano.

A ciclicidade da precipitação, ou seja, a repetição de máximos e mínimos a intervalos regulares pode ser avaliada com a aplicação do método da análise espectral (ou de Fourier) cuja significância estatística é dada pelo teste de Fisher. A variabilidade interanual foi determinada pelo coeficiente de variabilidade, obtido pela aplicação da fórmula:

$$
V_{\sigma}=\frac{\sigma}{P} \cdot 100
$$

na qual $\boldsymbol{\sigma}=$ desvio padrão da precipitação anual, e $\mathbf{P}=$ precipitação média anual.

O coeficiente é sempre superior a $25 \%$ nas regiões secas, excedendo a $40 \%$ ao longo da maioria das áreas marginais dos desertos (HARE, 1992).

Examinamos 237 séries distribuídas por todo o semi-árido, publicadas em Dados Pluviométricos Mensais do Nordeste (SUDENE, 1990), documento que constituiu a fonte de nossas informações. 


\section{Resultados obtidos}

O quadro geral da análise indicou $49,7 \%$ das séries apresentando tendência crescente nas médias pluviométricas, configurando uma distribuição geográfica indiferenciada, apresentando, contudo, incidência maior no Rio Grande do Norte, Paraíba e Pernambuco, sobretudo no espaço compreendido entre o reverso continental da Borborema e chapada do Apodi e seus prolongamentos meridionais. Tal constatação indica que a precipitação em nível regional acompanha a tendência de elevação da média pluviométrica que vem sendo registrada nas últimas décadas, presumivelmente associada ao agravamento do efeito de estufa.

Por outro lado, 50,3\% revelaram tendência estável ou decrescente, as primeiras, com distribuição geográfica mal caracterizada, ao passo que as segundas agruparam-se em quatro manchas, sinalizadoras de indícios de desertificação localizada.

A primeira, no Ceará, formando um eixo aproximadamente nordeste-sudoeste, que poderia ser considerada a diagonal árida desse Estado, desde Itapagé, em posição de sotavento em relação à serra de Uruburetama, até Campos Sales, no sopé da chapada do Araripe. Os pontos onde se detectou tendência negativa, ao longo dessa reta, foram os de Monsenhor Tabosa, Independência, Tauá e Arneiroz, além de duas localidades da média bacia do Jaguaribe (Quixadá e Mombaça), cujos coeficientes de variabilidade interanual revelaram-se acima de $45 \%$.

Em estudo publicado em 1993, a Fundação Cearense de Meteorologia e Recursos Hídricos (FUNCEME), baseado na interpretação visual e automática das imagens do satélite TM-LANDSAT, por meio da avaliação do grau de refletância das áreas com grande redução da biomassa, indicou duas manchas altamente degradadas no Estado do Ceará. A primeira coincidindo com a "diagonal árida" por nós assinalada, e a segunda, no vale médio do Jaguaribe. Tal resultado confirmou a pesquisa realizada, apesar das diferenças de metodologia (FUNCEME, 1993).

A segunda área de concentração de pontos com tendência pluviométrica negativa foi assinalada na parte deprimida correspondente à bacia média inferior do São Francisco, à jusante de Paulo Afonso, formando um polígono de aproximadamente $20 \mathrm{mil} \mathrm{km} 2$, com vértices em Santana de Ipanema (AL), Canudos (BA), Itabaiana (SE) e Propriá (SE), em cujo interior figuram mais quatro localidades com tendência negativa (Curralinho-SE, Mocambo-SE, Traipu-AL e Pão de Açúcar-AL), registrando-se, ainda, os maiores valores de duração da estação seca de todo o semi-árido: sete a dez meses. A terceira ocupa parte da Bahia, especialmente o médio São Francisco, a montante de Cabrobó, e a quarta abrange a bacia do rio de Contas, notadamente a região de Jequié.

Além dessas quatro maiores expressões espaciais, foram assinalados exemplos de tendência negativa em Açu e Caraúba, no Rio Grande do Norte, Umbuzeiro e Cabaceiras, na Paraíba, além de Caruaru, Brejo da Madre de Deus e Flores, em Pernambuco (Fig. 1).

A pesquisa indicou, também, pelo menos uma área em que o processo parece estar em recuo. Trata-se da parte meridional do agreste sergipano, entre Estância e Tobias Barreto, onde o clima úmido costeiro está ganhando espaço sobre o subúmido da faixa mais interiorizada, de acordo com 
a metodologia utilizada.

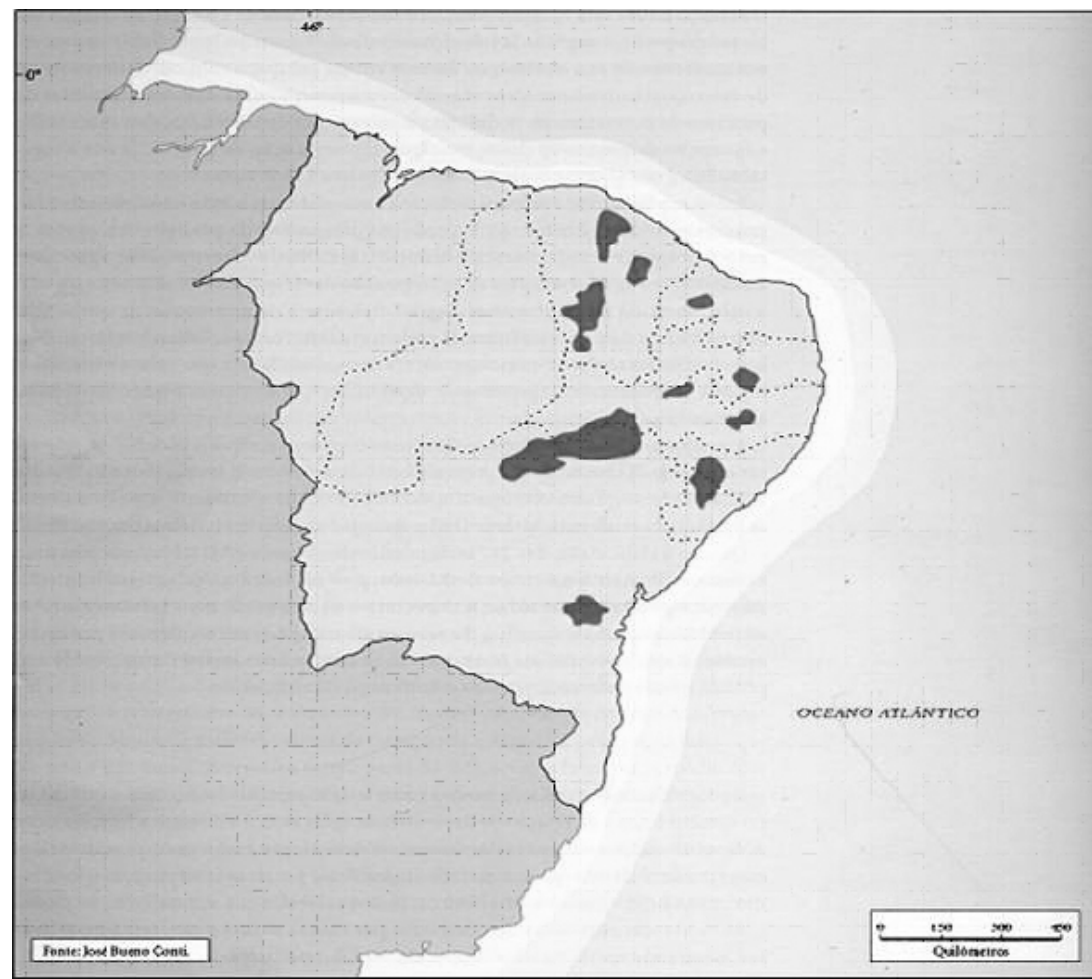

Figura 1. Área de concentração de pontos com tendência pluviométrica negativa no Nordeste brasileiro.

Quanto à ciclicidade, das 237 séries analisadas, apenas $43(18,1 \%)$ apresentaram ciclos, sendo mais freqüente o de 22 anos, porém, distribuídos, geograficamente, de forma pontual e aleatória. A expectativa de um perfil bem caracterizado de ciclicidade em todo o domínio do semi-árido não pode ser confirmada por nosso estudo. A alta variabilidade interanual da precipitação mascara flutuações de amplitude maior, descaracterizando o fenômeno da ciclicidade.

\section{Conclusões}

A geografia sempre se fundamentou na idéia da integração dos processos que atuam no quadro físico e da relação de dependência entre estes e a dinâmica da sociedade. A desertificação, como uma das formas de degradação ambiental, na maioria dos casos, nada mais é do que um dos resultados desse processo interativo, os quais, todavia, são heterogêneos e diacrônicos, cada qual tendo sua dimensão e seu ritmo.

As mudanças climáticas determinadas por causas naturais são, regra geral, lentas, ocorrendo na escala de milhares de anos, ao passo que as alterações produzidas pela ação antrópica manifestam-se em poucas décadas. No domínio semi-árido brasileiro, o fenômeno da desertificação vem se agravando como conseqüência da superexploração de um meio muito 
fragilizado pela escassez e variabilidade interanual das precipitações. A posição em baixa latitude expõe a região à intensa radiação solar, que exaure as reservas de água superficiais, ameaçando o equilíbrio da biosfera. É mais um exemplo de agressão ao ecúmeno.

Historicamente, essa parcela do território brasileiro vem sendo utilizada, desde o início do século XVIII, pela agricultura de subsistência e, especialmente, pela criação extensiva de gado. As relações de produção, porém, salvo raras exceções, sempre se caracterizaram pelo primitivismo dos procedimentos e por nenhuma preocupação de cunho preservacionista.

A estrutura fundiária, caracterizada pelo predomínio do latifúndio, deixa a imensa maioria dos habitantes da zona rural sem alternativas, a não ser o uso de áreas impróprias, sem acesso à água, de solos rasos e facilmente degradáveis, o que concorre para agravar enormemente a situação.

A remoção da rala cobertura vegetal natural a fim de obter combustível para uso doméstico e consumo em pequenas indústrias, as atividades mineradoras, especialmente no Rio Grande do Norte e no Piauí e outras formas de retirada dos recursos, foram e continuam sendo muito danosas para o ambiente.

Essas formas predatórias de relação com o meio produziram vastas áreas quase desérticas, com produtividade biológica reduzida a níveis mínimos, desde o Ceará até a Bahia, conforme procuramos demonstrar.

Os elevados valores dos coeficientes de variação interanual de precipitação confirmaram o caráter climaticamente transicional da região, que os estudiosos designam como efeito de borda, presente nas áreas marginais dos desertos e nos domínios semi-áridos, em geral.

Não seria incorreto afirmar que o avanço da desertificação está em relação direta com o grau de desenvolvimento econômico. Segundo estimativa do Pnuma, $86 \%$ das terras secas produtivas da África estão afetadas pela desertificação. Aí estão alguns dos países mais pobres do mundo tais como Senegal, Sudão, Mali, Chade e Etiópia, cujos valores de Produto Nacional Bruto (PNB) por habitante são, respectivamente, 720, 400, 280, 220 e 120 dólares. Por outro lado, a Austrália, cujo PNB é de 16500 dólares, tem apenas 22\% de suas terras produtivas atingidas pela desertificação.

Da mesma forma, é fundamental levar em conta o nível de informação dos habitantes, pois disso depende a avaliação adequada do problema e a escolha dos meios eficazes de combate. Nesse sentido, a educação é fator da maior importância.

No espaço geográfico brasileiro, é a região semi-árida do Nordeste que exibe os exemplos mais expressivos de desertificação, ou do que poderíamos chamar de aviltamento ambiental, como vimos. Castigada pela insuficiência e importantes desvios anuais das precipitações, solos litólicos, com reduzida capacidade de retenção de água, ventos quentes e secos, estimuladores da evaporação, a região tem essas condições desfavoráveis acentuadas nas depressões interplanálticas e nas vertentes a sotavento, em virtude do efeito orográfico de ressecamento.

Enfim, este estudo procurou caracterizar a desertificação dentro de uma metodologia climatológica, procurando situá-la no contexto dos riscos ambientais mais amplos, cuja incidência tem grande expressão nas baixas latitudes. Esta é uma oportunidade para estimular a reflexão sobre o significado 
da natureza e de seu papel como suporte da sociedade.

\section{Referências bibliográficas}

AB'SÁBER, A N. O Domínio Morfoclimático das Caatingas Brasileiras. São Paulo, IGEOG/USP, 1974 [Geomorfologia, 43].

- Problemática da Desertificação e da Savanização no Brasil Intertropical. São Paulo, IGEOG/USP, 1977 [Geomorfologia, 53].

FUNCEME (Fundação Cearense de Recursos Hídricos e Meteorologia) - Áreas degradadas susceptíveis de processo de desertificação no Estado do Ceará, 2a aproximação, Fortaleza. Secretaria de Estado de Recursos Hídricos, 1993.

GEIGER, P. P. - Introdução à análise de séries temporais. Revista Brasileira de Geografia. Rio de Janeiro, I.B.G.E. 36 (4): 81-108, 1974.

HARE, F. K. - Desertificação: causas e conseqüências. Lisboa. Fundação Calouste Gulbenkian, 1992.

MELO, M. L. - Paisagens do Nordeste em Pernambuco e Paraíba. Guia de Excursão n. ${ }^{0} 7$ do XVIII Congresso Internacional de Geografia. Rio de Janeiro. Conselho Nacional de Geografia, 1958.

MONTEIRO, C. A. F., On the Desertification in the Northeast Brazil and Man's Rule in this Process. The University of Tsukuba. Latin American Studies, n. 9. Ibaraki (Japan), 1988.

NIMER, E. - Desertificação: realidade ou mito? Revista Brasileira de Geografia. Rio de Janeiro, I.B.G.E. 50 (1): 7-39, 1988.

SUDENE - Dados pluviométricos mensais do Nordeste Brasileiro (11 volumes), Recife, 1990. 